\title{
An experimental study on charge optimization of a trans-critical $\mathrm{CO}_{2}$ cycle
}

\author{
C. Aprea · A. Greco $\cdot$ A. Maiorino
}

Received: 13 September 2013/Revised: 4 December 2013/Accepted: 11 January 2014/Published online: 30 January 2014 (C) Islamic Azad University (IAU) 2014

\begin{abstract}
The phasing out of hydrochlorofluorocarbon and chlorofluorocarbon fluids and further environmental problems arising from new, synthetic working fluids stimulate a continuously rising interest on natural candidates. The nontoxic and nonflammable $\mathrm{CO}_{2}$ impacts neither on ozone depletion nor on global warming if leaked to the atmosphere. The critical temperature of $\mathrm{CO}_{2}\left(31 .{ }^{\circ} \mathrm{C}\right)$ is almost ambient and, therefore, it undergoes a transcritical refrigeration cycle. In cooling mode operation, a trans-critical $\mathrm{CO}_{2}$ system, as compared to conventional airconditioners, has a lower performance which, contrary to conventional systems, strongly depends on the refrigerant charge. In this paper, the performance of the trans-critical system was evaluated experimentally under different refrigerant charge amounts. The influence of charge on coefficient of performance (COP), cooling capacity, compression ratio, suction line superheat was analyzed in detail. The experimental results indicate that the COP of the trans-critical cycle attains a maximum at optimal refrigerant charge. By varying the charge the cooling capacity attains a maximum, as well, that corresponds to the optimal charge. In order to understand the effect of refrigerant charge on the performance of each device of the plant, an exergetic analysis based on the experimental data was carried out. The analysis shows that the exergy flow destroyed in the compressor is one of the major causes of
\end{abstract}

C. Aprea $\cdot$ A. Maiorino

Dipartimento di Ingegneria Industriale, Università di Salerno, via

Ponte Don Melillo, 84084 Fisciano, Salerno, Italy

A. Greco $(\square)$

DII, Università degli Studi di Napoli Federico II,

P.le Tecchio 80, 80125 Naples, Italy

e-mail: adriana.greco@unina.it overall exergy destruction. At the optimal refrigerant charge, the compression losses attain a minimum.

Keywords $\mathrm{CO}_{2} \cdot$ Trans-critical cycle $\cdot$ Refrigerant charge $\cdot$ Coefficient of performance $\cdot$ Optimization

\section{Introduction}

The traditional refrigerants, i.e., chlorofluorocarbon (CFCs) and hydrochlorofluorocarbon (HCFCs) fluids, were banned by the Montreal Protocol (Montreal Protocol 1987) because of their contribution to the disruption of the stratospheric ozone layer (Molina and Rowland 1974). Indeed, according to the Kyoto Protocol, most hydrofluorocarbons (HFCs) have large global warming potentials (GWPs) and therefore provide a non-negligible, direct contribution to global warming when leaked to the atmosphere.

As a consequence, considerable research effort was devoted to the development of environmentally safe refrigeration systems using natural working fluids (Bhatkar et al. 2013). $\mathrm{CO}_{2}$ was considered as a promising alternative of HFCs. Indeed, carbon dioxide is a component of air, obtained from atmosphere itself by fractionation. Thus, it would have no impact on global warming, apart from for the energy consumption associated with the fractionation process.

$\mathrm{CO}_{2}$ has many excellent advantages in engineering applications, such as no toxicity, no inflammability, higher volumetric capacity that enables compact systems, lower pressure ratio, better heat transfer properties, complete compatibility with normal lubricants, easy availability, lower price and no recycling problems (Lorentzen and Petterson 1993; Lorentzen 1994, 1995; Liao et al. 2000; Bansal 2012). 
The critical temperature of $\mathrm{CO}_{2}\left(31.1{ }^{\circ} \mathrm{C}\right)$ is usually lower than typical heat rejection temperatures of air-conditioning and heat pump systems. This results in a transcritical vapor compression cycle in lieu of a conventional one in water heating and comfort cooling and heating (Rebora et al. 2006; Tagliafico et al. 2012).

Application of a trans-critical $\mathrm{CO}_{2}$ cycle to domestic water heating systems (Neksa et al. 1998; Neksa 2002) has advantages over conventional systems in terms of power consumption and heating efficiency (Hwang et al. 1999, 2001). The performance of trans-critical $\mathrm{CO}_{2}$ cooling system, however, is lower than that of conventional air-conditioners, due to large expansion losses and high irreversibility during the gas-cooling process (Aprea and Maiorino 2009a, b; Pérez-García et al. 2013). Therefore, many researchers analyzed the performance of the transcritical $\mathrm{CO}_{2}$ refrigeration cycle, in order to identify opportunities to improve the energy efficiency of the system (Kim et al. 2004).

Among the improvement methods, many researchers analyzed the effect of an internal heat exchanger (IHX) to reduce throttling losses. Boewe et al. (2001) indicated up to $25 \%$ COP improvements, as compared to the cycle without IHX. Mu et al. (2003) showed that larger IHX capacity can lower the optimum high-side pressure. Chen and $\mathrm{Gu}$ (2005) derived a practical expression for IHX effectiveness with a theoretical study and found that the latter is an important factor in achieving high cycle performance with a trans-critical cycle. Aprea and Maiorino (2008) showed that using the IHX, the COP is increased by $10 \%$. Tao et al. (2010) proposed that the IHX can reduce the throttling loss of the trans-critical cycle. Xu et al. (2011) investigated experimentally the effect of the IHX on a trans-critical $\mathrm{CO}_{2}$ ejector system. Experimental results showed that the IHX reduces the ejector contribution to the system performance.

Cabello et al. (2012) presented an experimental analysis of the energetic performances of a modified single-stage $\mathrm{CO}_{2}$ trans-critical refrigeration plant with an IHX based on vapor injection in suction line. Three different injection points have been evaluated experimentally. The measurements showed that the cooling capacity and the COP can be enhanced in 9.81 and $7.01 \%$, respectively.

Zhang et al. (2013) reported a theoretical study based on a thermodynamic analysis to study the effect of an IHX on the performance of an ejector-expansion trans-critical cycle. They found that adding an IHX does not necessarily improve the energetic performances in the ejector-expansion cycle, contrary to what occurs in a conventional throttling valve cycle.

Further improvements to system performance in reducing expansion losses are achieved by extracting and making use of the work potentially available from the process by means of an expander. A detailed parametric analysis (Robinson and Groll 1998) revealed that COP can increase if the expander efficiency is $30 \%$, but decreases when the expander isoentropic efficiency is $60 \%$.

Heidelck and Kruse (2000) discussed a new expander design based on a modified, reciprocating machine. Nickl et al. (2002) suggested a new expander-compressor design that provides a further $10 \%$ increase in COP and a $50 \%$ improvement over the same system with a throttle valve.

$\mathrm{Ma}$ et al. (2002) investigated the performance improvement of a $\mathrm{CO}_{2}$ cycle by applying an expander with a reciprocating, rotary or screw compressor with equivalent power consumption. Baek et al. (2005a, b: Part I and Part II) reported theoretical and experimental studies on a piston-cylinder work recovery.

In order to reduce expansion losses, an experimental investigation of the valve dynamics has been carried out by Ma et al. (2012). A semi-hermetic reciprocating compressor was developed with a test system incorporated into the compressor performance test rig, with a focus on investigating the dynamics of the discharge valves.

The performance deterioration of a basic, single-stage $\mathrm{CO}_{2}$ cycle can be improved using a multistage compressor and intercooling of liquid and vapor refrigerant. Inagaki et al. (1997) found that, for a two-stage $\mathrm{CO}_{2}$ air-conditioning cycle, capacity and COP are improved by 35 and $20 \%$, respectively, at moderate ambient temperature and by 10 and $5 \%$, respectively, at high ambient temperature. Halozan and Rieber (2000) and Kim and Kim (2002) studied the performance of an auto-cascade refrigeration cycle using $\mathrm{CO}_{2}$ as a working fluid. Huff et al. (2002) compared the performance of a two-stage $\mathrm{CO}_{2}$ cycle with that of a conventional one by means of a simplified model.

Hwang et al. (2000) carried out experimental studies on the performance of a two-stage $\mathrm{CO}_{2}$ cycle consisting in an intercooler and a flash tank. Groll et al. (2002) performed a thermodynamic analysis, focusing on the compression ratio in a trans-critical $\mathrm{CO}_{2}$ cycle with and without an expansion turbine.

Eskandari et al. (2012) proposed a theoretical model of a new two-stage multi-intercooling trans-critical $\mathrm{CO}_{2}$ refrigeration cycle with ejector-expansion device. In this cycle, the vapor compression line includes two intercoolers, the first with external coolant and the second with cycle refrigerant. The overall performance of the new cycle was compared with that of the conventional ejector refrigeration cycle (15.3\% higher) and with that of an IHX ejector refrigeration cycle (19.6\% higher).

To improve the COP of the cycle, an ejector can be used instead of a throttling valve to recover some of the kinetic energy of the expansion process. Liu et al. (2002) performed a thermodynamic analysis of the trans-critical $\mathrm{CO}_{2}$ vapor compression/ejection hybrid refrigeration cycle. $\mathrm{Li}$ 
and Groll (2005) proposed a theoretical model showing that the $\mathrm{COP}$ of a $\mathrm{CO}_{2}$ cycle can be improved by more than $16 \%$ with an ejector.

The performance of heat pumps and refrigeration systems with different refrigerant charge amounts was studied in many experimental and theoretical analyses (ASHRAE 1993; Palm 2007). Choi et al. (2002) studied the effects of improper refrigerant charge on the performance of a water-to-water heat pump using R22 as the refrigerant, with an electronic expansion valve and a capillary tube. In a further study (Choi et al. 2004), they tested the performance of R407C under various refrigerant charge and outdoor temperature conditions.

Cho et al. (2005) compared experimentally the performance of a $\mathrm{CO}_{2}$ cycle with that of other refrigerant systems, by varying the refrigerant charge amount.

Corberan et al. (2008) presented the experimental results regarding the optimization of the charge with a reversible water-to-water heat pump using propane as a refrigerant. Poggi et al. (2008) reported a review of refrigerant charge studies in refrigerant plants.

The considerable body of literature presented clearly underlines the problems related to the low-energetic performance of $\mathrm{CO}_{2}$ systems. Overall optimization of the plant performance is, therefore, mandatory. The performance of the trans-critical $\mathrm{CO}_{2}$ system strongly depends on refrigerant charge, much more than that of a conventional airconditioner. Surprisingly enough, whereas, in the literature, many papers deal with the influence of charge in traditional vapor compression plants: just one does in trans-critical ones. Therefore, the present paper intends to reduce the gap by presenting an ample database of experimental results on the performance of a $\mathrm{CO}_{2}$ trans-critical cycle at different refrigerant charges, in order: (1) to indentify the optimum amount of refrigerant maximizing cycle COP; (2) to evaluate the effect on cycle performance of undercharging or overcharging the plant; (3) to investigate the effect of refrigerant charge on the exergetic performance of each device of the plant.

The experimental tests discussed in this study are carried out with a prototype R744 system working as a classical split system to cool air in a trans-critical cycle.

The experimental prototype has been set up at the Cooling Techniques Laboratory of the University of Salerno. The experimental tests have been carried out from June to July 2012.

\section{Materials and methods}

Experimental plant

The experimental plant is described in Fig. 1 (Aprea and Maiorino 2009a, b; Aprea et al. 2012). Basically, there are

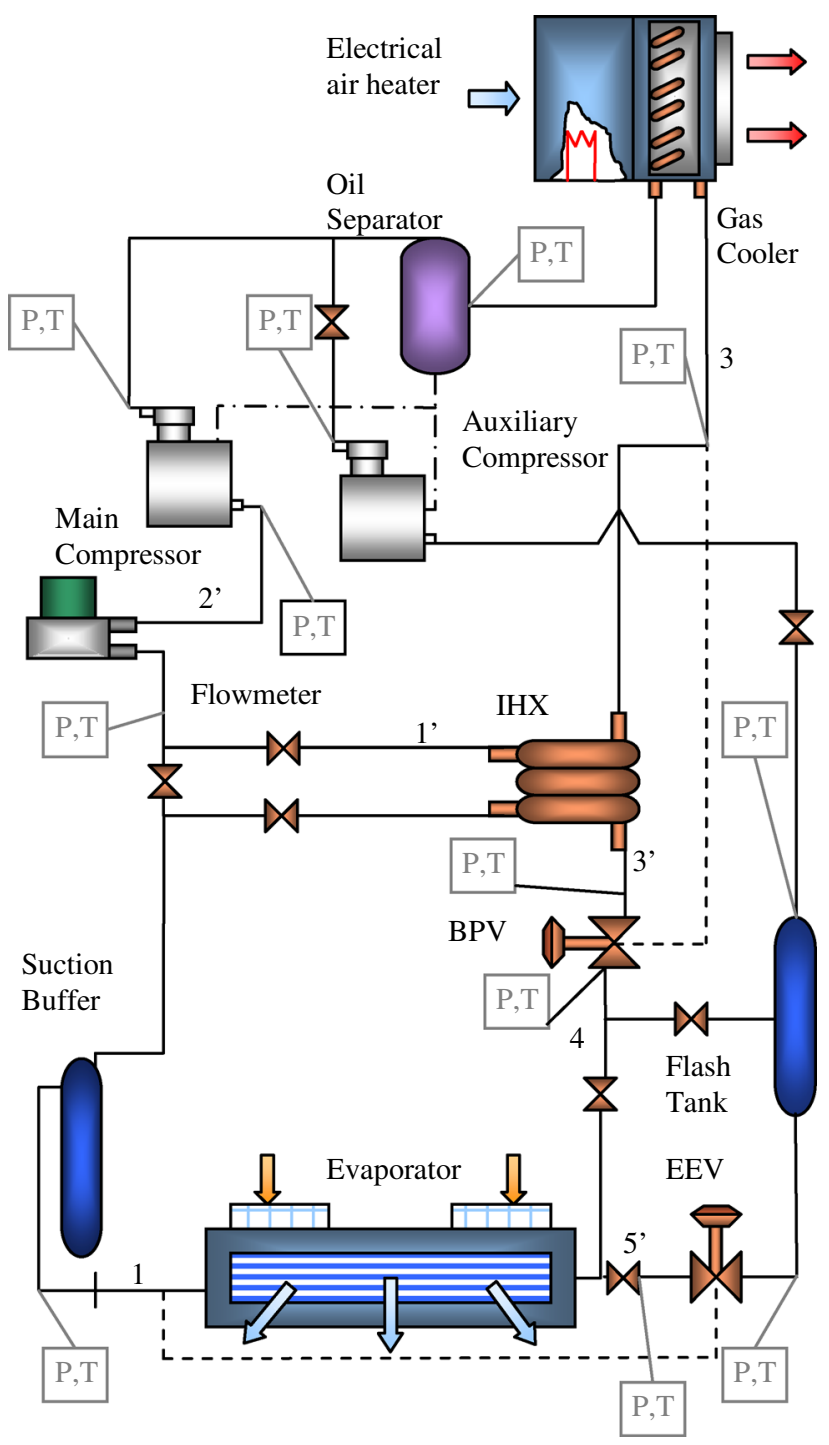

Fig. 1 A sketch of the experimental plant

two single-stage, semi-hermetic, reciprocating compressors, an oil separator, an air gas cooler, a liquid receiver, an air evaporator, an electronic expansion valve (EEV) and an electronically regulated back pressure valve (BPV).

An auxiliary compressor installed in a by-pass (Elbel and Hrnjak 2004) enables the analysis of the "flash vapor" influence. In a trans-critical cycle, the refrigerant at the inlet of the expansion device is typically a single-phase fluid with its high pressure exceeding the critical one. The refrigerant at the outlet of the expansion device is in a twophase condition, provided that the fluid crosses the saturated liquid line during the isenthalpic expansion process. As a result, some fraction of the refrigerant flow enters the evaporator in vapor state and thus does not provide a significant cooling effect. Because of the flash gas by-pass, the evaporator is fed with pure liquid and the vapor by-passes the evaporator through the auxiliary compressor circuit. A 
flash tank is used downstream of the back pressure valve. The flash tank acts as an accumulator storing refrigerant in excess for test conditions requiring smaller mass flow rates. Furthermore, it also acts as a separator where the liquid phase accumulates at the bottom, the vapor phase occupying the top.

The main compressor is a semi-hermetic one, and its working pressure range is $15-120$ bar. The intermediate pressure is of approximately 65 bar. Thus, the working pressure of the auxiliary, semi-hermetic compressor ranges from 55 to 120 bar. The nominal compression power for both compressors is $2.5 \mathrm{~kW}$.

At evaporation temperatures of 5 and of $30{ }^{\circ} \mathrm{C}$ at the gas cooler exit, where the pressure is $80 \mathrm{bar}$, the refrigerating power is of about $3,000 \mathrm{~W}$.

As discussed in (Aprea and Maiorino 2008), the use of the IHX in a carbon dioxide refrigeration split system improves the coefficient of performance (COP) by $10 \%$. Therefore, an IHX on the refrigerant line between compressor suction and the exit of the gas cooler was provided.

The lamination occurs thanks to the back pressure valve and to the electronic expansion one. Indeed, if a back pressure was employed as the only throttling device, it would not be possible to control the refrigerant mass flow rate, which is necessary to maintain the balance between refrigeration power and thermal load. Thus, in order to regulate the evaporation temperature, an auxiliary circuit can be used to by-pass the back pressure valve.

The air temperature on the gas cooler is modulated by some electrical resistances and an air flow driven by a blower located in a thermally insulated channel. This simulates variable external conditions, as well.

\section{System monitoring}

The plant is fully instrumented, in order to evaluate its performance as a whole, as well as that of each single component. Carbon dioxide pressure and temperature are measured at the inlet and at the outlet of each component. The working fluid mass flow rate is monitored at the main compressor suction (see Fig. 1).

Temperatures are measured by means of four-wire $100-\Omega$ platinum resistance thermometers with an accuracy of $\pm 0.15 \mathrm{~K}$. The sensors are located outside the pipe, with a layer of heat transfer compound (aluminum oxide plus silicon) placed between the sensor and the pipe to provide good thermal contact. The whole pipe is insulated with $25-\mathrm{mm}$-thick flexible insulation tape. The temperature measurement system is checked against a sensor positioned in a pocket in a similarly insulated pipe. The difference between the two measurements was always $<0.3{ }^{\circ} \mathrm{C}$.
Pressures are measured by piezoelectric sensors whose current output is recorded directly on the data logger. They were calibrated by the manufacturer in the range of $0-100$ bar with an accuracy of $\pm 0.8 \%$ F.S. Refrigerant mass flow rate is measured using a Micro Motion mass flow meter with an accuracy of $\pm 0.2 \%$. Two-watt transducers are used to measure the electrical power supplied to the compressors with an accuracy of $\pm 0.2 \%$. A balance is used to measure the refrigerant charge with an accuracy of $\pm 0.2 \%$.

An analysis was carried out, according to the procedure suggested by Moffat (1985), to evaluate the accuracy of the experimental data discussed in this paper.

The refrigerant power is evaluated as:

$\dot{Q}_{e v}=\dot{m}_{\mathrm{r}}\left(h_{\mathrm{r}, \mathrm{out}, \mathrm{ev}}-h_{\mathrm{r}, \mathrm{in}, \mathrm{ev}}\right)$

with an uncertainty range of $\pm 1.7-3.5 \%$.

The compression ratio is evaluated as:

$\beta=\frac{p_{\text {in.gc }}}{p_{\text {out.ev }}}$

with an uncertainty range of $\pm 2.1-2.7 \%$.

The COP is evaluated as:

$\mathrm{COP}=\frac{\dot{Q}_{\mathrm{ev}}}{\dot{W}}$

The uncertainty of $\dot{W}$ is $\pm 0.2 \%$. The COP uncertainty range is $\pm 1.8-3.8 \%$.

The volumetric efficiency is defined as:

$\eta_{\mathrm{v}}=\left(\frac{\dot{m}_{\mathrm{r}} v_{\mathrm{r}, \mathrm{suc}}}{\dot{V}_{\mathrm{suc}}}\right)$

where the displacement rate $\left(\dot{V}_{s u c}\right)$ is the volume swept through by the pistons in their suction strokes per unit time and is specified by the manufacturer. The uncertainty range of the latter parameter is $\pm 2.3-3.9 \%$.

Temperature and pressure at key points of the plant are continuously monitored, to verify that the apparatus is indeed operating in steady-state conditions.

A software application (ISAAC) has been developed in Labview (Labview ver.7.1) using REFPROP subroutines (REFRPROP ver.9.1). It provides real-time evaluations of the COP and of the enthalpies at all points of the thermodynamic cycle. Furthermore, it depicts the whole cycle on a $p-h$ diagram and checks that steady-state conditions actually hold. Figure 2 shows as an example a $p-h$ diagram of the trans-critical cycle with the IHX.

\section{Results and discussion}

The heater provides a fixed ambient temperature of $30{ }^{\circ} \mathrm{C}$.

Tests have been carried out by varying the refrigerant amount from 5.7 to $9 \mathrm{~kg}$ by progressively adding 


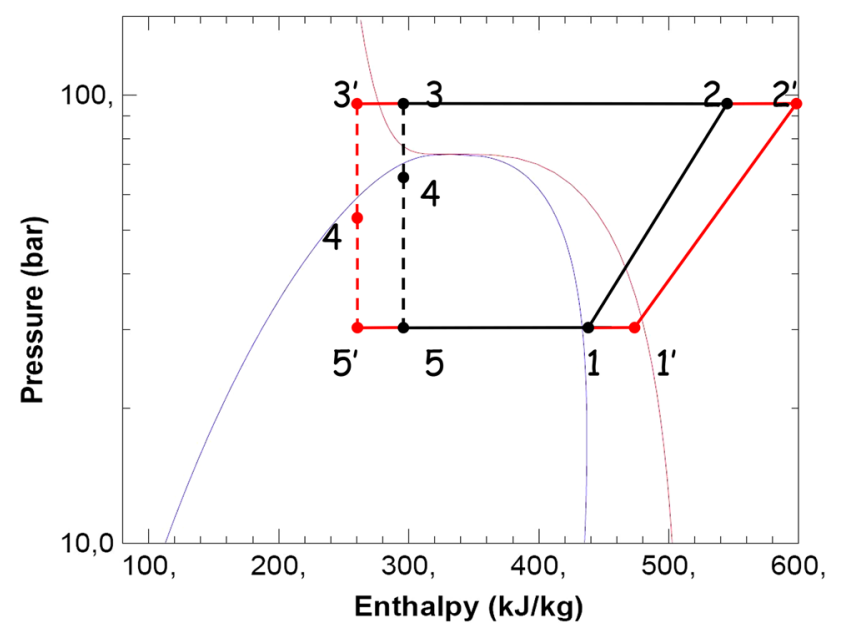

Fig. 2 A $p-h$ diagram of the trans-critical cycle with the internal heat exchanger

refrigerant into the system in 100 -g increments. In each test, the opening degree of the back up valve (BPV) is fixed.

$\mathrm{CO}_{2}$ refrigerant charge (RC) amount was normalized by the maximum refrigerant charge $\left(\mathrm{RC}_{\max }\right)$, i.e., by the maximum mass of saturated liquid at a room temperature of $25{ }^{\circ} \mathrm{C}$ :

$\mathrm{NC}=\frac{\mathrm{RC}}{\mathrm{RC}_{\max }}=\frac{\mathrm{RC}}{V \rho_{1}\left(25^{\circ} \mathrm{C}\right)}$

where $V$ is the volume of the whole plant $\left(0.0393 \mathrm{~m}^{3}\right)$.

Figure 3 reports $\mathrm{COP}$ as a function of the normalized refrigerant charge $(\mathrm{NC})$. It can be seen that $\mathrm{COP}$

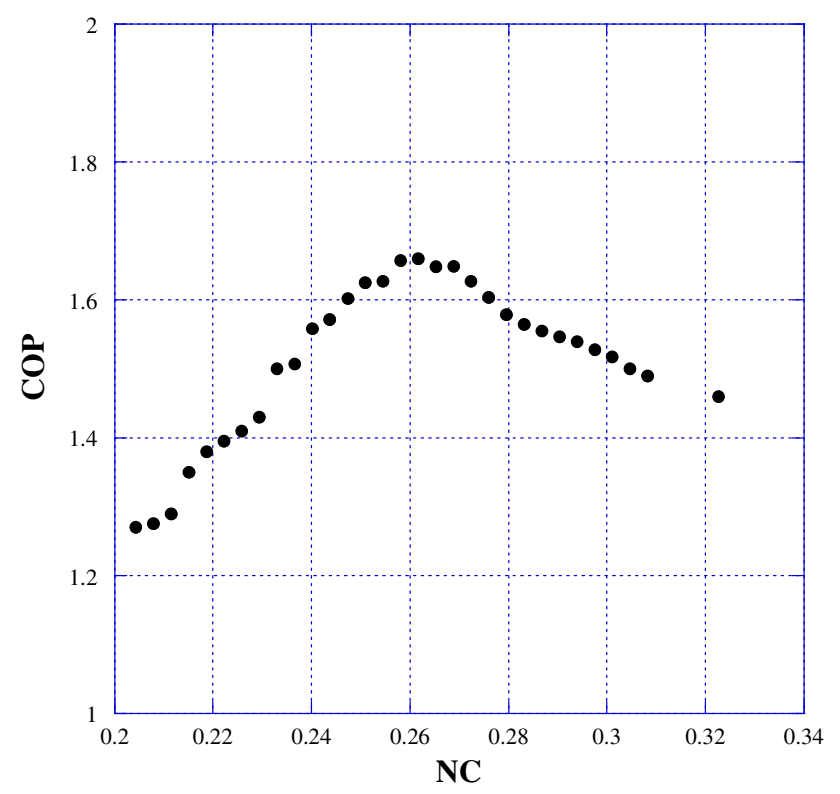

Fig. $3 \mathrm{COP}$ as a function of normalized refrigerant charge initially increases and then decreases with increasing refrigerant charge. The optimum refrigerant charge is 0.269 .

As the refrigerant charge increases, the system pressure increases in both the gas cooler and the evaporator. The pressure ratio decreases with the addition of refrigerant charge. When the system operates at low refrigerant charge, i.e., in undercharging conditions, the specific work of compression increases as a consequence of the thermodynamics properties and because the electric motor's windings are not properly cooled. As the refrigerant charge increases beyond its optimal value, COP decreases with the vaporization enthalpy.

Figure 4 reports the pressures in the gas cooler and in the evaporator, respectively, as a function of the NC. It is apparent that increasing the refrigerant charge increases both pressures. The pressure increase in the gas cooler under overcharging conditions $(\mathrm{NC}>0.269)$ can pose a security problem and the blowout disk might enter in action.

In Fig. 5 the compression ratio is reported as a function of refrigerant charge. The compression ratio decreases with the increasing refrigerant charge. As the refrigerant charge approaches the optimum value $(\mathrm{NC}=0.269)$, the slope of the compression ratio rapidly decreases.

Figure 6 shows the effect of NC on mass flow rate and indicates that the latter increases with refrigerant charge. Beyond the optimal value, the increase is quite limited. Indeed, by increasing the refrigerant charge, the compression ratio decreases, thus increasing the volumetric efficiency of the compressor.

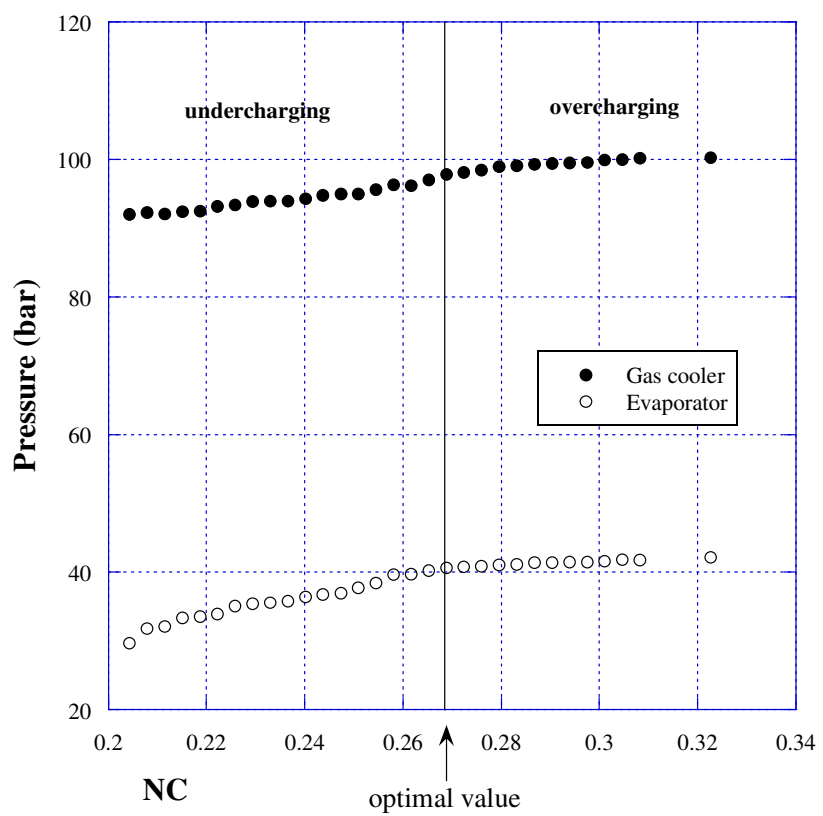

Fig. 4 Pressures in the evaporator and in the gas cooler as a function of normalized refrigerant charge 


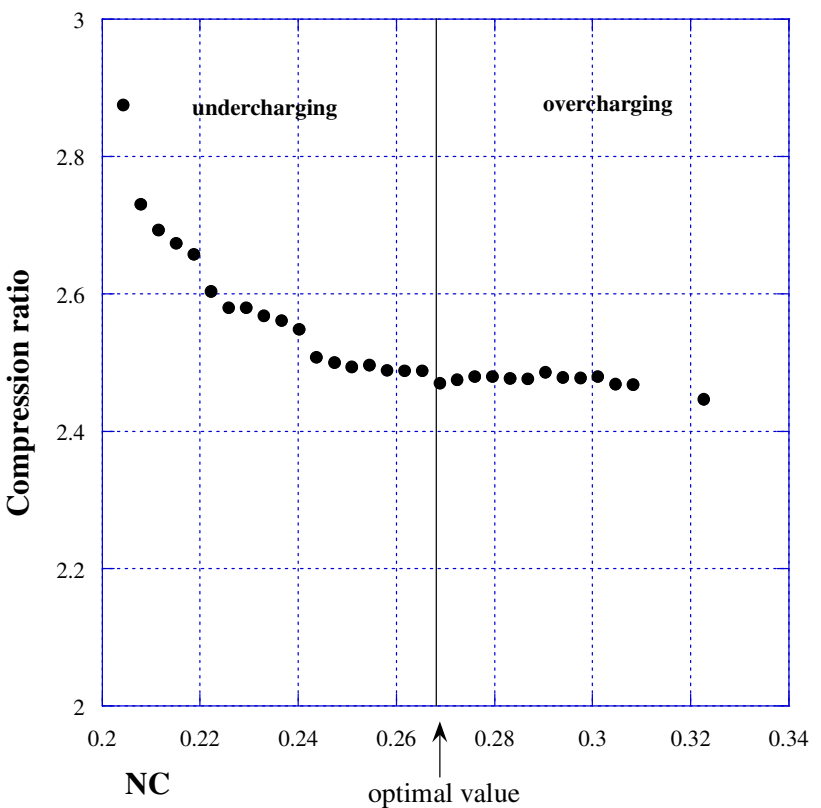

Fig. 5 Compression ratio as a function of normalized refrigerant charge

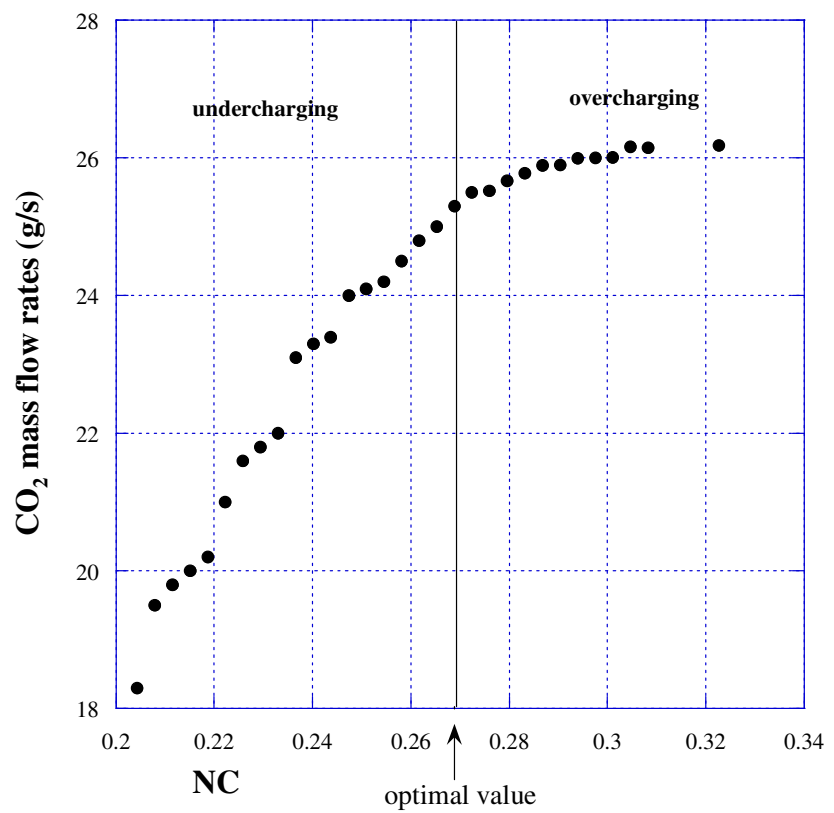

Fig. $6 \mathrm{CO}_{2}$ mass flow rate as a function of normalized refrigerant charge

Figure 7 indicates that vapor quality at the outlet of the back pressure valve decreases with increasing charge, eventually reaching very low values (near the conditions of saturated liquid) at overcharging. Indeed, the gas cooler pressure increases with refrigerant charge. The external temperature is fixed, and therefore, the temperature at the gas cooler exits too. This leads to a decrease in the enthalpy

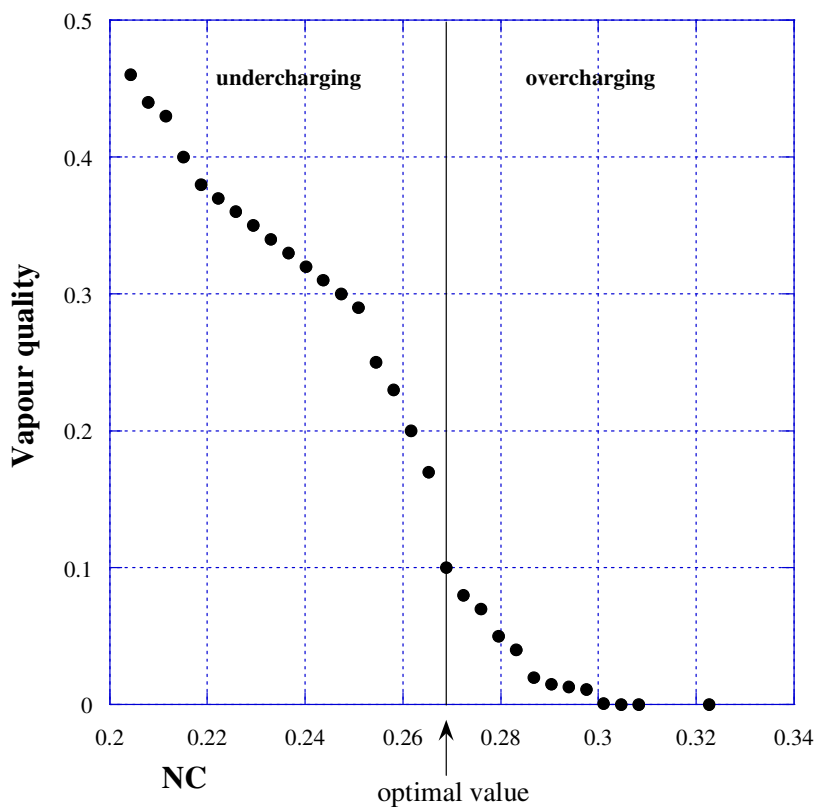

Fig. 7 Vapor quality at the outlet of the back pressure valve as a function of normalized refrigerant charge

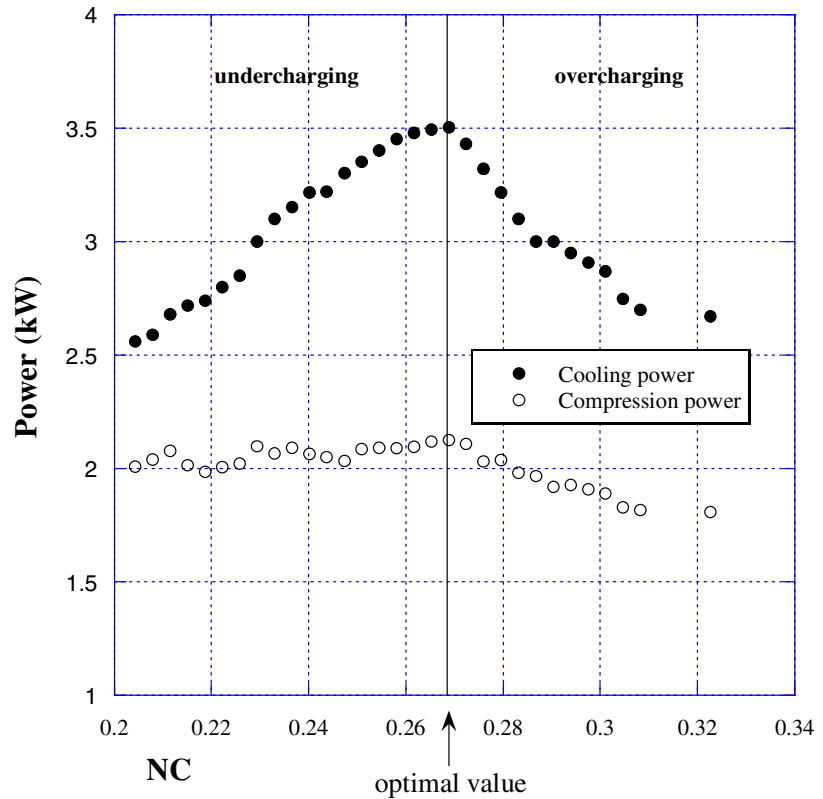

Fig. 8 Cooling capacity and compression power as a function of normalized refrigerant charge

at the outlet of this device decreasing the vapor quality at the evaporator inlet.

Figure 8 shows the variations in both cooling capacity and compression power with increasing NC. Initially, the compression power slightly increases and then decreases. Indeed, when the system operates in undercharging conditions, the specific work of compression slightly increases as a consequence of the corresponding increase in 
compressor suction pressure. This yields higher specific volume and mass flow rate. This increase is also because windings of the electric motor are not properly cooled. Under overcharging conditions, the power decreases because of the compressor malfunctioning. Indeed, at an excessive charge, liquid-phase refrigerant can reach the compressor. Furthermore, it should be noted that the cooling capacity increases with refrigerant charge, reaching a maximum. The maximum in cooling capacity corresponds to maximum COP. Indeed, by increasing the charge, refrigerant mass flow rate and the evaporating pressure both increase. For undercharged conditions, the cooling capacity increases with increasing charge, due to the increase in refrigerant mass flow rate and to the decrease in vapor quality at the inlet of the evaporator. For overcharged conditions, the cooling capacity decreases with increasing refrigerant charge, since the effect of the increase in evaporating pressure prevails. Indeed, beyond the optimal value, the increase in refrigerant mass flow rate is very limited and the refrigerant enthalpy at the evaporator outlet increases with increasing the evaporating pressure. This leads to a reduction in the specific variation of the vaporization enthalpy.

Table reports gas cooler pressure, evaporator pressure, compressor volumetric efficiency, temperature at the compressor inlet, as a function of the refrigerant charge. The results reported in Table 1 clearly show that the temperature at the inlet of the compressor always decreases increasing refrigerant charge. Indeed, at overcharging conditions, the superheating degree at the compressor inlet is very low and liquid refrigerant might reach the compressor. The volumetric efficiency always increases with refrigerant charge. Indeed, by increasing refrigerant charge, the compression ratio decreases thus increasing the compressor's volumetric efficiency.

In order to understand the effect of refrigerant charge on the performance of each device, an exergetic analysis based on experimental data was carried out. This analysis indicates the total plant irreversibility distribution among the plant components, pinpointing those that contribute most to overall plant-inefficiency.

The exergy flow destroyed in the evaporator is evaluated as:

$\dot{\mathrm{E}} \mathrm{x}_{\mathrm{des}, \mathrm{ev}}=\dot{m}_{\mathrm{r}}\left(\mathrm{ex}_{\mathrm{r}, \mathrm{in}, \mathrm{ev}}-\mathrm{ex}_{\mathrm{r}, \mathrm{out}, \mathrm{ev}}\right)-\dot{Q}_{\mathrm{ev}}\left|\tau_{\mathrm{ev}}\right|$

where the dimensionless exergetic temperature of the air flow in the evaporator can be defined as:

$\tau_{\mathrm{ev}}=1-\frac{T_{\mathrm{o}}}{T_{\mathrm{TMT}, \mathrm{a}, \mathrm{ev}}}$

The exergy flow destroyed in the gas cooler is evaluated:
Table 1 Gas cooler and evaporator pressures, compressor volumetric efficiency and temperature at the inlet of the compressor as a function of refrigerant charge

\begin{tabular}{lllll}
\hline Charge $(\mathrm{kg})$ & $p_{\text {ev }}(\mathrm{bar})$ & $p_{\text {gc }}(\mathrm{bar})$ & $\eta_{\mathrm{v}}$ & $T_{\text {in,cp }}\left({ }^{\circ} \mathrm{C}\right)$ \\
\hline 5.7000 & 29.677 & 92.000 & 0.65568 & 13.230 \\
5.8000 & 31.828 & 92.300 & 0.66780 & 12.800 \\
5.9000 & 32.091 & 92.100 & 0.67900 & 12.300 \\
6.0000 & 33.357 & 92.400 & 0.68000 & 12.000 \\
6.1000 & 33.514 & 92.500 & 0.68800 & 11.900 \\
6.2000 & 33.891 & 93.200 & 0.69300 & 11.700 \\
6.3000 & 35.113 & 93.400 & 0.69800 & 11.500 \\
6.4000 & 35.434 & 93.900 & 0.69900 & 11.400 \\
6.5000 & 35.602 & 93.990 & 0.70010 & 11.330 \\
6.6000 & 35.741 & 94.000 & 0.71200 & 11.000 \\
6.7000 & 36.409 & 94.300 & 0.72300 & 10.920 \\
6.8000 & 36.744 & 94.800 & 0.73100 & 10.410 \\
6.9000 & 36.962 & 94.993 & 0.73600 & 9.8000 \\
7.0000 & 37.698 & 95.000 & 0.74400 & 9.6600 \\
7.1000 & 38.404 & 95.626 & 0.75500 & 9.3300 \\
7.2000 & 39.630 & 96.300 & 0.76900 & 9.1200 \\
7.3000 & 39.755 & 96.208 & 0.77900 & 8.7000 \\
7.4000 & 40.251 & 97.005 & 0.79900 & 8.5000 \\
7.5000 & 40.606 & 97.850 & 0.80300 & 8.3300 \\
7.6000 & 40.738 & 98.171 & 0.80600 & 8.2200 \\
7.7000 & 40.868 & 98.481 & 0.81100 & 8.1100 \\
7.8000 & 41.076 & 98.982 & 0.81900 & 8.0200 \\
7.9000 & 41.119 & 99.093 & 0.82200 & 7.9800 \\
8.0000 & 41.368 & 99.300 & 0.82900 & 7.8200 \\
8.1000 & 41.436 & 99.460 & 0.83400 & 7.7900 \\
8.2000 & 41.460 & 99.520 & 0.83900 & 7.5900 \\
8.3000 & 41.506 & 99.614 & 0.84200 & 7.4300 \\
8.4000 & 41.619 & 99.928 & 0.84900 & 7.4200 \\
8.5000 & 41.841 & 100.00 & 0.85300 & 7.3800 \\
8.6000 & 41.785 & 100.20 & 0.85500 & 7.3100 \\
9.0000 & 42.143 & 100.30 & 0.86200 & 7.2200 \\
\hline & & & &
\end{tabular}

$\dot{\mathrm{Ex}}_{\mathrm{des}, \mathrm{gc}}=\dot{m}_{\mathrm{r}}\left(\mathrm{ex}_{\mathrm{r}, \mathrm{in}, \mathrm{gc}}-\mathrm{ex}_{\mathrm{r}, \mathrm{out}, \mathrm{gc}}\right)-\dot{Q}_{\mathrm{gc}} \tau_{\mathrm{gc}}$

where the dimensionless exergetic temperature of the air flow in the gas cooler can be defined as:

$\tau_{g c}=1-\frac{T_{o}}{T_{T M T, a, g c}}$

The exergy flow destroyed in the compressor, neglecting the heat transfer with the environment, is evaluated as:

$\dot{\mathrm{Ex}} \mathrm{x}_{\mathrm{des}, \mathrm{cp}}=\dot{m}_{\mathrm{r}}\left(\mathrm{ex}_{\mathrm{r}, \mathrm{in}, \mathrm{cp}}-\mathrm{ex}_{\mathrm{r}, \mathrm{out}, \mathrm{cp}}\right)+\dot{W}$

The exergy flow destroyed in each valve (BP and EEV) is evaluated as: 


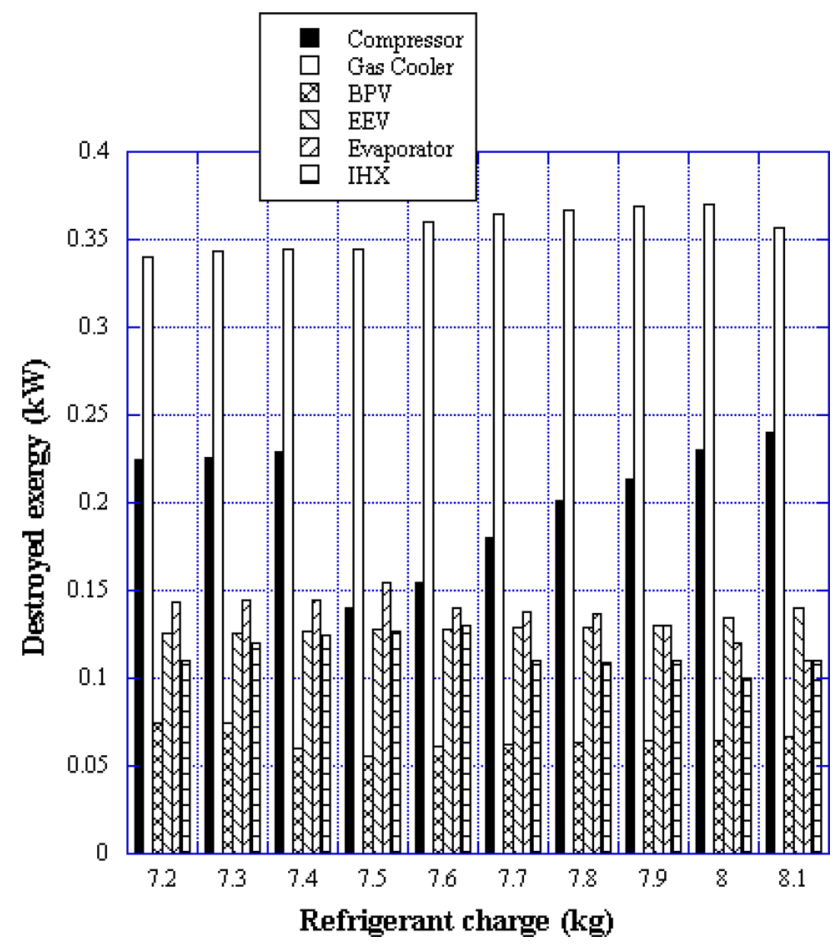

Fig. 9 Destroyed energy in the devices of the experimental plant as a function of refrigerant charge

$\dot{\mathrm{Ex}} \mathrm{x}_{\mathrm{des}, \mathrm{v}}=\dot{m}_{\mathrm{r}}\left(\mathrm{ex}_{\mathrm{r}, \mathrm{in}, \mathrm{v}}-\mathrm{ex}_{\mathrm{r}, \mathrm{out}, \mathrm{v}}\right)$

The exergy flow destroyed in the IHX is evaluated as:

$\dot{\mathrm{Ex}}_{\mathrm{des}, \mathrm{ihx}}=\dot{m}_{\mathrm{r}}\left(\mathrm{ex}_{\mathrm{r}, \text { in } 1, \mathrm{ihx}}-\mathrm{ex}_{\mathrm{r}, \text { out } 1, \mathrm{ihx}}\right)_{1}$

$$
+\dot{m}_{\mathrm{r}}\left(\mathrm{ex}_{\mathrm{r}, \mathrm{in} 2, \mathrm{ihx}}-\mathrm{ex}_{\mathrm{r}, \mathrm{out} 2, \mathrm{ihx}}\right)
$$

Figure 9 reports the exergy flow destroyed in each component of the plant as a function of the refrigerant charge.

Figure 9 clearly shows that the exergy loss in the gas cooler predominates and accounts for more than $30 \%$ of the total exergy loss. The exergy losses in this device are not affected significantly by refrigerant charge.

The exergy flow destroyed in the compressor is one of the major causes of exergy destruction in the plant. The refrigerant charge strongly affects the exergy losses in this device. Under both overcharging and undercharging conditions, the compressor losses amount to approximately $22 \%$ of the total losses. At the optimal refrigerant charge, the compression losses are $15 \%$ of the total. When the system operates at low refrigerant charge, the specific work of compression increases as a consequence of the thermodynamic properties and because the electric motor's windings are not properly cooled. When the refrigerant charge yielding a correct cooling of the electric motor's windings, the compression power attains a minimum. As the refrigerant charge increases beyond the optimal value, the compressor power consumption increases because the increase in suction pressure in the compressor results in higher specific volume and mass flow rate.

\section{Conclusion}

The performance of the trans-critical system is more sensitive to refrigerant charge amount than that of a conventional air-conditioner. System performance stem is critically linked to an appropriate mass charge. In the present paper, the effects of refrigerant charge were analyzed by means of an experimental prototype, working as a classical spit system to cool air in a trans-critical cycle.

The COP of the trans-critical cycle attains a maximum value corresponding to the optimal refrigerant charge $(7.5 \mathrm{~kg})$.

In order to characterize the effects of refrigerant charge, a detailed analysis was carried out on the major parameters affecting cycle performances by varying the charge from -32 to $+17 \%$ of the optimal value. In this range, plant COP varies between -21 and $-7.5 \%$ of the optimal value. Therefore, the COP reduced more significantly at undercharged conditions than at overcharged.

As the refrigerant charge increases, the system pressure increases in both gas cooler and evaporator, thus decreasing the compression ratio. The volumetric compressor's efficiency decreases with increasing refrigerant mass flow rate. The vapor quality at the inlet of the evaporator decreases due to a reduction in the enthalpy at the exit of the gas cooler. Initially, the compression power slightly increases and then decreases with increasing charge. Indeed, at an excessive charge, liquid refrigerant can reach the compressor. The cooling capacity increases with refrigerant charge reaching a maximum and then decreases. The maximum in cooling capacity corresponds to the maximum COP.

In order to understand the effect of refrigerant charge on the performance of each device of the plant, an exergetic analysis based on the experimental data was carried out. This analysis shows that the exergy flow destroyed in the compressor is one of the major causes of exergy destruction in the plant. The refrigerant charge strongly affects the exergy losses in this device. Under both overcharging and undercharging conditions, the compressor losses amount to about $22 \%$ of the total. At the optimal refrigerant charge, the compression losses are $15 \%$ of the total. Therefore, at the optimal refrigerant charge, the compression losses attain a minimum.

Acknowledgments The financial support of University of Salerno was gratefully acknowledge. (FARB UNIVERSITY OF SALERNO 
NR. ORSA072593,"Indagine sperimentale su un impianto frigorifero a compressione operante con l'anidride carbonica").

\section{List of symbols}

Symbols

BPV Back pressure valve

COP Coefficient of performance

ex Specific exergy $(\mathrm{J} / \mathrm{kg})$

Ex $\quad$ Exergy flow (W)

EEV Electronic expansion valve

$h \quad$ Specific enthalpy $(\mathrm{kJ} / \mathrm{kg})$

IHX Internal heat exchanger

$\dot{m}_{\mathrm{r}} \quad$ Refrigerant mass flow rate $(\mathrm{kg} / \mathrm{s})$

NC Normalized charge

$\dot{Q} \quad$ Heat transfer rate $(\mathrm{kW})$

RC Refrigerant charge ( $\mathrm{kg})$

$\mathrm{SC} \quad$ Specific charge $(\mathrm{kg} / \mathrm{kW})$

$T$ Temperature $\left({ }^{\circ} \mathrm{C}, \mathrm{K}\right)$

$T_{\mathrm{o}} \quad$ Ambient temperature $\left({ }^{\circ} \mathrm{C}, \mathrm{K}\right)$

$v \quad$ Specific volume $\left(\mathrm{m}^{3} / \mathrm{kg}\right)$

$\dot{V} \quad$ Volumetric flow rate $\left(\mathrm{m}^{3} / \mathrm{s}\right)$

$\dot{W} \quad$ Compression power $(\mathrm{kW})$

Greek symbols

$\beta$ Compression ratio

$\eta_{\mathrm{v}} \quad$ Volumetric efficiency

$\tau \quad$ Dimensionless exergetic temperature

Subscripts

$\begin{array}{ll}\text { a } & \text { Air } \\ \text { des } & \text { Destroyed } \\ \text { cp } & \text { Compressor } \\ \text { ev } & \text { Evaporative } \\ \text { ev } & \text { Evaporator } \\ \text { gc } & \text { Gas cooler } \\ \text { in } & \text { Inlet } \\ \text { IHX } & \text { Internal heat exchanger } \\ \text { max } & \text { Maximum } \\ \text { TMT } & \text { Mean thermodynamic } \\ \text { out } & \text { Outlet } \\ \text { r } & \text { Refrigerant fluid } \\ \text { suc } & \text { Suction } \\ \text { v } & \text { Expansion valve }\end{array}$

\section{References}

Aprea C, Maiorino A (2008) An experimental evaluation of the transcritical $\mathrm{CO}_{2}$ refrigerator performances using an internal heat exchanger. Int J Refrig 31:1006-1011

Aprea C, Maiorino A (2009a) Transcritical $\mathrm{CO}_{2}$ refrigerator and subcritical R134a refrigerator: a comparison of the experimental results. Int J Energy Res 33:1040-1047

Aprea C, Maiorino A (2009b) Heat rejection pressure optimization for a carbon dioxide split system: an experimental study. Appl Energy 861:2373-2380

Aprea C, Greco A, Maiorino A (2012) An experimental evaluation of the greenhouse effect in the substitution of $\mathrm{R} 134 \mathrm{a}$ with $\mathrm{CO}_{2}$. Energy 45:753-761

ASHRAE Standards 116 (1993), Methods of testing for seasonal efficiency of unitary air-conditioner and heat pumps. ASHRAE Standards 116. Atlanta (GA), ASHRAE

Baek JS, Groll EA, Lawless PB (2005a) Piston cylinder work producing expansion device in a carbon dioxide cycle. Part I: experimental investigation. Int J Refrig 28:141-151

Baek JS, Groll EA, Lawless PB (2005b) Piston cylinder work producing expansion device in a carbon dioxide cycle. Part I: theoretical investigation. Int J Refrig 28:152-164

Bansal P (2012) A review-status of $\mathrm{CO}_{2}$ as a low temperature refrigerant: fundamental and $\mathrm{R} \& \mathrm{D}$ opportunities. Applied Therm Eng 41:18-29

Bhatkar VW, Kriplani VM, Awari GK (2013) Alternative refrigerants in vapour compression refrigeration cycle for sustainable environment: a review of recent research. Int J Env Sci Technol 10(7):871-880

Boewe D, Bullard C, Yin J, Hrnjak PS (2001) Contribution of internal heat exchanger to transcritical R744 cycle performance. Int J HVAC\&R Res 7(2):155-168

Cabello R, Sànchez D, Patiño J, Llipis R, Torrella E (2012) Experimental analysis of energy performance of modified single-stage $\mathrm{CO}_{2}$ transcritical vapour compression cycles based on vapour injection in the suction line. Appl Therm Eng 47:86-94

Chen Y, Gu JJ (2005) The optimum high pressure for $\mathrm{CO}_{2}$ transcritical refrigeration systems with an internal heat exchangers. Int J Refrig 28(8):1238-1249

Cho C, Ryu Y, Kim H, Kim Y (2005) Effects of refrigerant charge amount on the performance of a transcritical $\mathrm{CO}_{2}$ heat pump. Int J Refrig 28:1266-1273

Choi JM, Kim YC (2002) The effects of improper charge on the performance of a heat pump with an electronic expansion valve and capillary tube. Energy 27:391-404

Choi JM, Kim YC (2004) Influence of expansion device on the performance of a heat pump using $\mathrm{R} 407 \mathrm{C}$ under a range of charging conditions. Int J Refrig 45:378-384

Corberán J, Martínez IO, Gonzálvez J (2008) Charge optimization study of a reversible water-to-water propane heat pump. Int J Refrig 31:716-726

Elbel S, Hrnjak P (2004) Flash gas bypass for improving the performance of transcritical R744 systems that use microchannel evaporators. J Refrig 7:724-735

Eskandari NF, Yavari MA (2012) Performance of a new two-stage multi intercooling transcritical $\mathrm{CO}_{2}$ ejector refrigeration cycle. Appl Therm Eng 40:202-209

Groll EA, Baek S, Lawless PB (2002) Effect of pressure ratio across compressors on the performance of the transcritical $\mathrm{CO}_{2}$ cycle with two-stage compression and intercooling, The International Refrigeration and Air Conditioning Conference, Purdue, R11-7 
Halozan $\mathrm{H}$, Rieberer $\mathrm{R}$ (2000) $\mathrm{CO}_{2}$ as a refrigerant possible application, The Fourth IIR-Gustav Lorentzen conference on natural working fluids, Purdue, pp 43-50

Heidelck R, Kruse H (2000) Expansion machines for carbon dioxide bases on modified reciprocating machines, The Fourth IIRGustav Lorentzen conference on natural working fluids, West Lafayette, pp 455-462

Huff HJ, Hwang Y, Radermacher R (2002) Options for a two-stage transcritical carbon dioxide cycle, The Fifth IIR-Gustav Lorentzen conference on natural working fluids, Guangzhou, China, pp 143-149

Hwang Y, Radermacher R (1999) Experimental investigation of the $\mathrm{CO}_{2}$ refrigeration cycle. ASHRAE Trans 105(1):1219-1227

Hwang Y, Celik A, Radermacher R (2000) Performance of $\mathrm{CO}_{2}$ cycles with a two-stage compressor, The Fourth IIR-Gustav Lorentzen conference on natural working fluids, Purdue, p 105

Hwang Y, Huff $\mathrm{H}$, Preissner R, Radermacher R (2001) $\mathrm{CO}_{2}$ transcritical cycles for high temperature application, Proc. ASME Int Congr 2001, New York, pp 255-260

Inagaki M, Sasaya H, Osakli Y (1997) Pointing to the future: two stage $\mathrm{CO}_{2}$ compression, heat transfer issues in natural refrigerants. Int Inst Refrig 24:131-140

Kim SG, Kim MS (2002) Experiment and simulation on the performance of an autocascade refrigeration system using carbon dioxide as a refrigerant. Int J Refrig 25:1093-1101

Kim MH, Petterson J, Bullard CW (2004) Fundamental process and system design issues in $\mathrm{CO}_{2}$ vapor compression systems. Prog Energy Combust Sci 30:119-174

Labview ver. 7.1, National Instruments Software

Li D, Groll EA (2005) Transcritical $\mathrm{CO}_{2}$ refrigeration cycle with ejector-expansion device. Int J Refrig 28:766-773

Liao SM, Zhao TS, Jakobsen A (2000) A correlation of optimal heat rejection pressures in transcritical carbon dioxide cycles. Appl Therm Eng 20(9):831-841

Liu JP, Chen JP, Chen ZJ (2002) Thermodynamic analysis on the transcritical R744 vapor-compression/ejection hybrid refrigeration cycle, The Fifth IIR-Gustav Lorentzen conference on natural working fluids, Guangzhou, China, pp 184-188

Lorentzen G (1994) Revival of carbon dioxide as a refrigerant. Int J Refrig 17(5):292-301

Lorentzen G (1995) The use of natural refrigerants: a complete solution to the $\mathrm{CFC} / \mathrm{HCHC}$ predicament. Int $\mathrm{J}$ Refrig 18(3):190-197

Lorentzen G, Petterson J (1993) A new efficient and environmentally benign system for air-conditioning. Int J Refrig 16(1):4-12

Ma Y, Wei D, Za S, Li M (2002) Thermodynamic analysis and compression expander for $\mathrm{CO}_{2}$ transcritical cycle, The Fifth IIRGustav Lorentzen conference on natural working fluids, Guangzhou, China, pp 292-297

Ma Y, He Z, Peng X, Xing Z (2012) Experimental investigation of the discharge valve dynamics in a reciprocating compressor for trans-critical $\mathrm{CO}_{2}$ refrigeration cycle. Appl Therm Eng 32:13-21
Moffat RJ (1985) Using uncertainty analysis in the planning of an experiment. Trans ASME J Fluids Eng 107:173-178

Molina MJ, Rowland FS (1974) Stratospheric sink for chlorofluoromethanes: chlorine atom catalyzed destruction of ozone. Nature 249:810-812

Montreal Protocol on substances that deplete the ozone layer (1987). New York, NY

Mu JY, Chen JP, Chen ZJ (2003) System design and analysis of the transcritical carbon dioxide automotive air-conditioning system. J Zhejiang Univ Sci A 4(3):305-308

Neksa P (2002) $\mathrm{CO}_{2}$ heat pump systems. Int J Refrig 25:421-427

Neksa P, Rekstad H, Zakeri P, Schiefloe P (1998) $\mathrm{CO}_{2}$ heat pump water heater: characteristics, system design and experimental results. Int J Refrig 21:172-179

Nickl J, Will G, Kraus W, Quack H (2002) Design considerations for a second generation $\mathrm{CO}_{2}$-expander, The Fifth IIR-Gustav Lorentzen conference on natural working fluids, Guangzhou, China, pp 189-196

Palm B (2007) Refrigeration systems with minimum charge of refrigerant. Appl Therm Eng 27:1693-1701

Pérez-García V, Belman-Flores JM, Navarro-Esbrí J, Rubio-Maya C (2013) Comparative study of transcritical vapour compression configurations using $\mathrm{CO}_{2}$ as a refrigeration mode base on simulation. Appl Therm Eng 51:1038-1046

Poggi F, Macchi-Tejeda H, Leducq D, Bontemps A (2008) Review: refrigerant charge in refrigerating systems and strategies of charge reduction. Int J Refrig 31:353-370

Rebora A, Senarega M, Tagliafico LA (2006) Influence of some design parameters on the thermal performance of domestic appliances. Heat Mass Transf 42:803-811

REFPROP ver.9.1 (2010) NIST Thermodynamic properties of refrigerants and refrigerant mixtures database. US Dept. of Commerce, Gaithersburg

Robinson D, Groll E (1998) Efficiencies of transcritical $\mathrm{CO}_{2}$ cycle with and without an expansion turbine. Int $\mathrm{J}$ Refrig 21(7):577-589

Tagliafico LA, Scarpa F, Tagliafico G (2012) A compact dynamic model for household vapour compression refrigerated systems. Appl Therm Eng 35:1-8

Tao YB, He YL, Tao WQ, Wu ZG (2010) Experimental study on the performance of $\mathrm{CO}_{2}$ residential air-conditioning system with an internal heat exchanger. Energy Convers Manage 51(4):64-70

Xu X, Chen G, Tang L, Zhu Z, Liu S (2011) Experimental evaluation of the effect of an internal heat exchanger on a transcritical $\mathrm{CO}_{2}$ ejector system. J Zhejiang Univ Sci A 12(2):146-153

Zhang Z, Ma Y, Wang H, Li M (2013) Theoretical evaluation on the effect of internal heat exchanger in ejector expansion transcritical $\mathrm{CO}_{2}$ refrigeration cycle. Appl Therm Eng 50:932-938 